\title{
Differences of Ventricular Late Potential between Acute STEMI and NSTEMI Patients
}

\author{
J Wang, X-T Sui, Y-X Sun, Y Li, G Yang, F Xu, Y-L Zhang, X-G Zhang
}

\begin{abstract}
Objective: To discuss the positive rate of ventricular late potential (VLP) between patients with acute ST-segment elevation myocardial infarction (STEMI) and patients with acute non NSTEMI.

Methods: One hundred and sixty-three cases of acute myocardial infarction (90 patients with STEMI and 73 with NSTEMI), admitted to the First Hospital of China Medical University between June 2011 and August 2011, underwent VLP examination.

Results: The VLP positive rate of the STEMI group was $54.4 \%$, while that of the NSTEMI group was $38.4 \%$, and the differences have statistical meaning $\left(\chi^{2}=4.186, \mathrm{p}<0.05\right)$. The occurrence rate of ventricular arrhythmia in VLP positive patients was $11.7 \%$, while in VLP negative patients it was $3.5 \%$ $\left(\chi^{2}=4.005, \mathrm{p}<0.05\right)$.

Conclusion: The VLP positive rate of the STEMI group is higher than that of the NSTEMI group.
\end{abstract}

Keywords: Acute non ST-segment elevation myocardial infarction, acute ST-segment elevation myocardial infarction, ventricular arrhythmia, ventricular late potential

\section{Diferencias del Potencial Tardío Ventricular entre Pacientes con Infartos Agudos STEMI Y NSTEMI

\author{
J Wang, X-T Sui, Y-X Sun, Y Li, G Yang, F Xu, Y-L Zhang, X-G Zhang
}

\begin{abstract}
RESUMEN
Objetivo: Analizar la tasa positiva del potencial tardio ventricular (PTV) entre pacientes con infarto agudo del miocardio sin elevación del segmento ST (NSTEMI por sus siglas en inglés) y el infarto agudo del miocardio con elevación del segmento ST (STEMI por sus siglas en inglés)

Métodos: Ciento sesenta y tres casos de infarto agudo de miocardio (90 pacientes con STEMI) y 73 con NSTEMI, ingresados en la Universidad Primer Hospital de Medicina China entre junio y agosto de 2011, fueron sometidos a examen de PTV.

Resultados: La tasa positiva PVT del grupo STEMI fue 54.4\%, mientras que la del grupo NSTEMI fue $38.4 \%$, y las diferencias tienen significado estadístico $\left(\chi^{2}=4.186, p<0.05\right)$. La tasa de ocurrencia de arritmia ventricular en pacientes PVT positivos fue $11.7 \%$, mientras que en los pacientes PVT negativos fue $3.5 \%\left(\chi^{2}=4.005, p<0.05\right)$.

Conclusión: La tasa PTV positiva del grupo STEMI es mayor que la del grupo NSTEMI.
\end{abstract}

Palabras claves: Infarto agudo del miocardio sin elevación del segmento ST, infarto agudo del miocardio con elevación del segmento ST, arritmia ventricular, potencial tardío ventricular

West Indian Med J 2013; 62 (8): 721

From: Department of Cardiology, The First Hospital of China Medical University, Shenyang 110001, China.

Correspondence: Dr Y-X Sun, Department of Cardiology, The First Affiliated Hospital of China Medical University, No 155, North Nanjing Street, Heping District, Shenyang 110001, Liaoning Province, China. Fax: 86-24-83282688, e-mail: sunyingxian12@yahoo.com

\section{INTRODUCTION}

Ventricular late potential [VLP] (1-6) is the high-frequency low-amplitude cardiac potential that appears at the end of the QRS complex and extends to the ST segment. It is the manifestation of delayed depolarization in regional myocardium, which is the main factor that leads to re-entrant ventricular 
tachycardia. In recent years, the detection and clinical significance of VLP in coronary artery disease patients has received more attention, especially the significance of ventricular arrhythmia prediction in acute myocardial infarction patients. However, there was no research about the clinical features of VLP between patients with acute ST-segment elevation myocardial infarction (STEMI) and patients with acute non STEMI. Thus, the objective of this paper is to discuss the positive rate of VLP between STEMI patients and NSTEMI patients.

\section{SUBJECTS AND METHODS}

Research subjects were randomly recruited between June 2011 and August 2011 from inpatients at the Department of Cardiology of the First Hospital of China Medical University (Shenyang, China). The patients were included if they presented with a new-onset acute myocardial infarction (AMI), defined as having typical chest pain of $>30$ minutes duration or electrocardiogram (ECG) changes compatible with AMI, or both, and total serum creatine-kinase levels at least twice the upper limit of normal range with abnormal creatine kinase-MB or troponin levels. Patients who met any of the following criteria were excluded: past history of myocardial infarction, left or right bundle-branch block, intraventricular conduction abnormalities (QRS duration > 120 milliseconds) and if the patient refused to undergo VLP examination.

A total of 186 AMI patients met the inclusion criteria, but 23 of these also met one or more exclusion criteria and were excluded, including 11 patients who had past history of myocardial infarction, seven patients who had left or right bundle-branch block, one patient with intraventricular conduction abnormalities and four patients who refused to undergo VLP examination. Thus, a total of 163 AMI patients were included as subjects in this study.

The 163 cases of AMI patients were divided into STEMI group and NSTEMI group according to whether the ST segment was raised: 90 cases were in the STEMI group, and 73 cases in the NSTEMI group. All 163 cases underwent VLP examination. The occurrences of ventricular arrhythmia (ventricular fibrillation, ventricular flutter and sustained ventricular tachycardia) were determined by continuous ECG monitoring.

The study was approved by the Ethics Committee of China Medical University. Participants signed a written consent form before participating.

\section{Measurement of VLP obtained from signal-averaged ECG}

Signal-averaged electrocardiogram (SAECG) was analysed using a signal-averaged ECG system (MAC 5500 Resting ECG Analysis System, made by General Electric Company). The quantitative time domain mode with the filtered vector magnitude of the orthogonal Frank $\mathrm{x}, \mathrm{y}$, and $\mathrm{z}$ leads were used to measure VLPs, with frequency cut-off between 40 and $250 \mathrm{~Hz}$. Approximately 200 beats were filtered and averaged. The noise level was controlled below $0.4 \mu \mathrm{V}$. Three quantitative parameters of SAECG were considered to assess the presence of VLPs using a computer algorithm: (i) the filtered QRS duration (f-QRS) of 114 milliseconds or more; (ii) the duration of the low-amplitude signal (LAS) of $<40 \mu \mathrm{V}$ in the terminal portion of the filtered QRS complex of 38 milliseconds or more and (iii) the root mean square (RMS) voltage of the terminal 40 millisecond of the filtered QRS of $20 \mu \mathrm{V}$ or less. Ventricular late potentials were present when at least two of these showed abnormal values (1, 5).

\section{Statistical analysis}

The positive rate of VLP and the occurrence rate of malignant ventricular arrhythmia were treated as enumeration data. The comparison between STEMI and NSTEMI groups was calculated by Chi-squared test, using SPSS 19.0 software. A pvalue of $<0.05$ was considered statistically significant.

\section{RESULTS}

\section{Characteristics of patients}

Of the 90 STEMI patients (STEMI group), 57 patients were male, and 33 patients were female. The mean age of the STEMI group was $61.6 \pm 12.4$ years. Of the 73 NSTEMI patients (NSTEMI group), 53 patients were male, and 20 patients were female. The mean age of the NSTEMI group was $63.5 \pm 13.1$ years (Table 1 ).

Table 1: Characteristics of patients

\begin{tabular}{lcc}
\hline & STEMI group & NSTEMI group \\
\hline Gender (male, \%) & $63.3 \% \%^{\mathrm{a}}$ & $72.6 \%^{\mathrm{a}}$ \\
Age (year) & $61.6 \pm 12.4^{\mathrm{a}}$ & $63.5 \pm 13.1^{\mathrm{a}}$ \\
Complicated with hypertension (\%) & $54.4 \%^{\mathrm{a}}$ & $52.1 \%^{\mathrm{a}}$ \\
Complicated with diabetes mellitus (\%) & $33.3 \%^{\mathrm{a}}$ & $24.7 \%^{\mathrm{a}}$ \\
Cigarette smoking (\%) & $57.8 \%^{\mathrm{a}}$ & $52.1 \%^{\mathrm{a}}$ \\
Alcohol abuse (\%) & $15.6 \%^{\mathrm{a}}$ & $15.1 \%^{\mathrm{a}}$ \\
Killip classification $\geq$ level 2 (\%) & $35.6 \%^{\mathrm{a}}$ & $38.4 \%^{\mathrm{a}}$ \\
Peak value of cTnI (ng/ml) & $92.2 \pm 78.2^{\mathrm{b}}$ & $13.8 \pm 16.3^{\mathrm{b}}$ \\
Left ventricular end diastolic & & \\
diameter (mm) & $52.3 \pm 4.9^{\mathrm{a}}$ & $53.3 \pm 7.5^{\mathrm{a}}$ \\
Left ventricular ejection fraction (\%) & $49.8 \pm 9.6^{\mathrm{a}}$ & $52.5 \pm 10.3^{\mathrm{a}}$ \\
Use of aspirin and clopidogrel & & \\
simultaneously & $97.8 \% \mathrm{a}^{\mathrm{a}}$ & $97.3 \% \mathrm{a}^{\mathrm{a}}$ \\
Use of beta-blocker drugs & $92.2 \%^{\mathrm{a}}$ & $93.2 \%^{\mathrm{a}}$ \\
\hline
\end{tabular}

a: comparison between STEMI and NSTEMI groups $p>0.05$; b: comparison between STEMI and NSTEMI groups, $p<0.05$

STEMI $=$ ST-segment elevation myocardial infarction, NSTEMI $=$ non STsegment elevation myocardial infarction

In the STEMI group (90 patients), 49 (54.4\%) patients had positive VLP, while in the NSTEMI group (73 patients), $28(38.4 \%)$ patients had positive VLP. The differences have statistical meaning $\left[\chi^{2}=4.186, p<0.05\right]$ (Table 2). 
Table 2: Comparison of VLP positive rate between STEMI and NSTEMI groups $[\mathrm{n},(\%)]$

\begin{tabular}{lcc}
\hline Group & VLP positive & VLP negative \\
\hline STEMI group & $49(54.4 \%)$ & $41(45.6 \%)$ \\
NSTEMI group & $28(38.4 \%)$ & $45(61.6 \%)$ \\
\hline
\end{tabular}

$\chi^{2}=4.186, p<0.05$

$\mathrm{VLP}=$ ventricular late potential, STEMI $=$ ST-segment elevation myocardial infraction, NSTEMI = non ST-segment elevation myocardial infraction

Of 77 VLP positive patients, nine patients had ventricular arrhythmia, while of 86 VLP negative patients, three patients had ventricular arrhythmia. The occurrence rate of ventricular arrhythmia in VLP positive patients was $11.7 \%$, while in VLP negative patients it was $3.5 \%\left[\chi^{2}=\right.$ $4.005, p<0.05$ ] (Table 3).

Table 3: The occurrence rate of ventricular arrhythmia between ventricular late potential (VLP) positive patients and VLP negative patients

\begin{tabular}{lcc}
\hline Patients & $\begin{array}{c}\text { Ventricularia } \\
\text { arrhythmia }\end{array}$ & $\begin{array}{c}\text { No ventricular } \\
\text { arrhythmia }\end{array}$ \\
\hline VLP positive patients & $9(11.7 \%)$ & 68 \\
VLP negative patients & $3(3.5)$ & 83 \\
\hline
\end{tabular}

$\chi^{2}=4.005, p<0.05$

\section{DISCUSSION}

Ventricular late potentials are low-amplitude and highfrequency waveforms within the terminal portion of the QRS complex. Routine ECG signals cannot record VLPs due to simultaneous biological and environmental electrical signals known as noise. The process of averaging QRS complexes reduces these non-cardiac signals without modifying VLPs, and the SAECG is a specialized ECG which reveals the presence of VLPs by reducing the random noise. The value of VLP that is closely related to sudden death as an independent factor to predict the malignant arrhythmia events after myocardial infarction is widely recognized (1-7).

Ventricular late potential exists in the border zone between normal tissue and necrotic scar tissue of myocardial infarction patients. A slow conduction "channel" has been reported to be frequently found in the viable myocardium that is bordered by such necrotic scar tissue. The nonconductive ventricular scar and the "channel" are the mechanisms that create the occurrence of lethal ventricular arrhythmias (8). In the present study, the VLP positive rate of the STEMI group is higher than that of the NSTEMI group, and the differences are statistically significant. In STEMI patients, the infarction is "transmural" in that it extends through the full thickness of the cardiac wall, thus we speculate this might be the reason why the VLP positive rate of the STEMI group is higher than that of the NSTEMI group, and it needs further study.

Ventricular late potentials reflect the presence of slow conduction within the ventricular myocardium that may serve as a substrate for arrhythmogenesis (5-9). In the present study, the occurrence rate of ventricular arrhythmia in VLP positive patients is higher than that in VLP negative patients, and VLP is one of the important indicators to predict the ventricular arrhythmia attack in acute myocardial infarction patients. Therefore, close attention should be paid to the patients with VLP positive myocardial infarction and continuous ECG monitoring should be used promptly as well as treatment started early in order to reduce the occurrence of ventricular arrhythmia.

\section{ACKNOWLEDGEMENTS}

This research is financially supported by National Science and Technology Support Programme of China (Project number: 2012BAJ18B02).

\section{REFERENCES}

1. Tsutsumi T, Takano N, Matsuyama N, Higashi Y, Iwasawa K, Nakjma T. High-frequency powers hidden within QRS complex as an additional predictor of lethal ventricular arrhythmias to ventricular late potential in post-myocardial infarction patients. Heart Rhythm 2011; 8: 1509-15.

2. Benchimol-Barbosa PR, Muniz RT. Ventricular late potential duration correlates to the time of onset of electrical transients during ventricular activation in subjects' post-acute myocardial infarction. Int J Cardiol 2008; 129: 285-7.

3. Pandey AK, Das A, Singwala AK, Bhatt KN. Prediction and stratification of the future cardiovascular arrhythmic events: signal averaged electrocardiography versus ejection fraction. Indian J Physiol Pharmacol 2010; 54: 123-32.

4. Nakahara S, Tung R, Ramirez RJ, Gima J, Wiener I, Mahajan A. Distribution of late potentials within infarct scars assessed by ultra highdensity mapping. Heart Rhythm 2010; 7: 1817-24.

5. Gomes JA, Cain ME, Buxton AE, Josephson ME, Lee KL, Hafley GE et al. Prediction of long-term outcomes by signal-averaged electrocardiography in patients with unsustained ventricular tachycardia, coronary artery disease, and left ventricular dysfunction. Circulation 2001; 104: 436-41.

6. Hsia HH, Lin D, Sauer WH. Relationship of late potentials to the ventricular tachycardia circuit defined by entrainment. J Interv Card Electrophysiol 2009; 26: 21-9.

7. Matveev M, Krasteva V, Naydenov S, Donova T. Possibilities of signalaveraged orthogonal and vector electrocardiography for locating and size evaluation of acute myocardial infarction with ST-elevation. Anadolu Kardiyol Derg 2007; 7 (Suppl 1): 193-7.

8. Takase B, Nagata M. Delayed enhancement morphology on cardiac magnetic resonance imaging is correlated with signal-averaged electrocardiogram and QT dispersion in myocardial infarction. Angiology 2009; 60: 412-18

9. Saha P, Goldberger JJ. Risk stratification for prevention of sudden cardiac death. Curr Treat Options Cardiovasc Med 2012; 14: 81-90. 